\title{
Valores de referência da hemoglobina glicada e frutosamina em cães
}

\section{Reference values of glycosylated haemoglobin and fructosamin in dogs}

\author{
Olair Carlos Beltrame ${ }^{1 *}$; Rosangela Locatelli Dittrich ${ }^{2}$; Nina Cunha Medeiros ${ }^{1}$; \\ Marília Oliveira Koch ${ }^{1}$; Lia Fordiani Lenati Patrício ${ }^{1}$; Bruno Queiroz Castilhos ${ }^{3}$; \\ Mariana Pavelski; ${ }^{4}$ Luciane Maria Laskoski ${ }^{4}$
}

\begin{abstract}
Resumo
A hemoglobina glicada e frutosamina são pouco utilizadas em cães para o diagnóstico do Diabetes mellitus devido à escassez e divergência de valores de referência. Com o objetivo de determinar os valores de referência e metodologia da hemoglobina glicada e frutosamina em cães, foram utilizados 100 cães sadios, machos e fêmeas, de dois a oito anos. As metodologias empregadas foram resina de troca iônica e método cinético por redução do azul de nitrotetrazólio, respectivamente. Os valores médios de hemoglobina glicada encontrados foram de 5,3-7,01\% e de frutosamina de 277,52-387,3 $\mu \mathrm{molL}^{-1}$, estabelecidos segundo metodologias da Sociedade Brasileira de Diabetes, e podem ser adotados para cães, machos e fêmeas.
\end{abstract}

Palavras-chave: Cães, frutosamina, hemoglobina glicada, glicose

\begin{abstract}
Glycated haemoglobin and fructosamin levels are not commonly used to diagnosis Diabetes mellitus in dogs due to a lack of reference values. To estabilish the reference values and determination methods of glycated haemoglobin and frutosamine, both male and females, healthy dogs, 2-8 years old $(n=100)$ were used. The methodologies used were the ionic resin and the kinetic method by the reduction of blue nitrotetrazolium, respectively. Medium values of glycated haemoglobin of 5.3-7.01\% and 277.52-387. 30 for fructosamin established by Brazilian Diabetes Society methods can be adopted for dogs, both males and females.
\end{abstract}

Key words: Dog, fructosamin, glycated haemoglobin, glucose

\footnotetext{
1 Discentes de Mestrado do curso de Pós Graduação em Ciências Veterinárias, Universidade Federal do Paraná, UFPR, Curitiba, PR.E-mail: beltrame@ufpr.br; ninadcm@hotmail.com; mariliakoch@hotmail.com; lialenati@gmail.com

2 Prof ${ }^{\mathrm{a}}$, curso de Pós Graduação em Ciências Veterinárias, UFPR, Curitiba, PR. E-mail: roslocodi@ufpr.br

3 Médico Veterinário, UFPR, Curitiba, PR. E-mail: bruno_caltilhos@yahoo.com.br

4 Discentes de Doutorado, curso de Pós Graduação em Ciências Veterinárias, UFPR, Curitiba, PR. E-mail: marimedvet@gmail. com; luci.laskoski@gmail.com

* Autor para correspondência
} 


\section{Introdução}

O Diabetes Mellitus é uma doença endócrina comum em cães, caracterizada pela secreção insuficiente ou ausente de insulina pelo pâncreas, que causa um estado de hiperglicemia. $O$ tratamento da doença é realizado com a administração exógena de insulina, no entanto, requer um monitoramento regular para que a terapia seja apropriada (RUCINSKY et al., 2010).

Nas últimas décadas, a ocorrência da doença vem aumentando consideravelmente em cães e gatos, o que pode estar associado ao aumento da expectativa de vida dos animais (PLOTNICK; GRECO, 1995; HOENING, 2002).

As dosagens da hemoglobina glicada e da frutosamina são úteis para monitorar a eficiência do tratamento do Diabetes mellitus, e muito utilizadas em pessoas, pois refletem o histórico dos níveis de glicemia em longo prazo, sendo considerados exames padrão ouro para o controle da doença (HINDLE et al., 1986).

A hemoglobina glicada resulta da ligação não enzimática da hemoglobina $\mathrm{A}(\mathrm{HbA})$ com a glicose, de forma contínua, lenta e irreversível. A hemácia é permeável à glicose, desta forma, a hemoglobina é exposta às mesmas concentrações da glicose plasmática, acumulando-se dentro das hemácias na forma de hemoglobina glicada (PEACOCK, 1984).

A frutosamina é uma proteína glicada que resulta da ligação da glicose com a proteína sérica total ou a albumina. É decorrente de ligação não enzimática, irreversível e dependente dos valores da glicemia (KANEKO, 2008). No cão, a dosagem da frutosamina reflete os níveis de glicose plasmática uma ou duas semanas antecedentes à dosagem de glicemia (JENSEN; AAES, 1992; KAWAMOTO et al., 1992).

O monitoramento do diabetes em cães e gatos, por determinação das proteínas glicadas, não é realizado na rotina clínica. Nos poucos relatos dos parâmetros de referência para hemoglobina glicada e frutosamina, os valores foram discrepantes, variáveis de acordo com a metodologia utilizada e foram determinados em poucos animais (KANEKO, 2008).

Portanto, os objetivos deste estudo são determinar os valores de referência da hemoglobina glicada e frutosamina em cães e padronizar a metodologia para sua determinação.

\section{Material e Métodos}

Foram utilizados 100 cães machos e fêmeas, sadios, com níveis glicêmicos constantemente normais. Os critérios de inclusão foram: idade de dois a oito anos, clinicamente saudáveis e níveis de glicose sanguínea persistente de até $110 \mathrm{mgdL}^{-}$ 1. As amostras de sangue foram coletadas por venopunção jugular, sendo $3 \mathrm{~mL}$ armazenados em tubo com anticoagulante (ácido etilenodiamino tetra-acético) destinados à avaliação do hemograma e hemoglobina glicada e $3 \mathrm{~mL}$ foram acondicionados sem anticoagulante. $\mathrm{O}$ soro foi obtido por centrifugação para posterior realização de análises bioquímicas.

A contagem de eritrócitos, leucócitos e a concentração da hemoglobina foram determinados em contador automático CELM CC530 (CELM, Barueri, Brasil). Os demais parâmetros hematológicos foram determinados segundo Waner et.al. (2000). Os esfregaços sanguíneos foram corados com Panótico Rápido LB (Laborclin, Pinhais/PR Brasil).

Foram mensuradas as concentrações séricas de glicose, alanina amino tranferase (ALT), aspartato amino tranferase (AST), fosfatase alcalina (FA), ureia, creatinina, proteínas totais, albumina e frutosamina em analisador semi-automático CELM SBA 200 (CELM, Barueri/SP, Brasil) com kits comerciais (Human Brasil Itabira/SP, Brasil).

A hemoglobina glicada e a frutosamina foram determinadas, respectivamente, pelos métodos de resina de troca iônica (Human Brasil, Itabira/SP, 
Brasil) e cinético por redução do tetrazólio nitroazul (NBT) (Labtest, Lagoa Santa/MG, Brasil), em espectrofotômetro Quick-Lab (Dreake, São José do Rio Preto/SP, Brasil), a $530 \mathrm{~nm}$.

\section{Resultados e Discussão}

Os parâmetros hematológicos e bioquímicos dos cães do presente estudo permaneceram dentro dos valores de referência. Os valores médios da hemoglobina glicada e da frutosamina obtidos foram de 5,35 - 7,05 e de 273,51-382,29 $\mu \mathrm{molL}^{-1}$, respectivamente (Tabela 1). Para os valores da hemoglobina glicada e frutosamina não foram verificadas diferenças significativas entre machos e fêmeas "Teste t de student".

Tabela 1. Valores médios, desvio padrão e intervalos mínimo e máximo das concentrações sanguíneas de hemoglobina glicada $(\mathrm{Hb})$, frutosamina e glicose em cães sadios, machos e fêmeas.

\begin{tabular}{lccccc}
\hline Parâmetros/Animais & \multicolumn{2}{c}{ Machos } & \multicolumn{2}{c}{ Fêmeas } & Média geral \\
\hline $\begin{array}{l}\text { Hb glicada } \\
(\%)\end{array}$ & $6,1 \pm 0,87^{\mathrm{a}}$ & $5,23-6,97$ & $6,2 \pm 0,85^{\mathrm{a}}$ & $5,35-7,05$ & $6,2 \pm 0,85$ \\
$\begin{array}{l}\text { Frutosamina } \\
(\mu \mathrm{mol} / \mathrm{L})\end{array}$ & $342,6 \pm 57,2^{\mathrm{b}}$ & $285,4-399,8$ & $322,2 \pm 52,55^{\mathrm{b}}$ & $269,65-374,8$ & $327,9 \pm 54,39$ \\
$\begin{array}{l}\text { Glicose } \\
(\mathrm{mg} / \mathrm{dL})\end{array}$ & $94,9 \pm 10,9^{\mathrm{C}}$ & $84-105,8$ & $95,2 \pm 12,3^{\mathrm{C}}$ & $82,9-107,5$ & $95,1 \pm 11,9$ \\
\hline
\end{tabular}

Letras iguais na mesma coluna indicam médias sem diferença estatística significante $(\mathrm{p}>0,05)$.

Fonte: Elaboração dos autores.

Em estudo realizado por Wood e Smith (1980) observou-se resultado de hemoglobina glicada para cães não diabéticos de 4,97\% e em animais com diabetes o valor foi de 9,63\%. Elliott et al. (1997) encontraram valor média de 3,3\% para cães saudáveis, realizando a dosagem da hemoglobina glicada. Os resultados diferem dos valores encontrados neste trabalho (valores médios entre $5,35-7,05 \%$ ) possivelmente devido às diferentes metodologias utilizadas na determinação da hemoglobina glicada.

Neste estudo, foi utilizado o método de resina de troca iônica, o mesmo adotado para seres humanos e aprovado pela Sociedade Brasileira de Diabetes. Esta técnica pode ser empregada para cães, pois as frações de hemoglobina do eritrócito humano são idênticas as do eritrócito do cão (BRIMHAELL; DUERST; JONES, 1997).

A hemoglobina glicada reflete os níveis médios da glicose sanguínea dos dois meses anteriores a coleta da amostra, porque a hemácia do cão tem meia vida aproximada de 60 dias. O controle glicêmico do cão deve ser realizado determinandose a hemoglobina glicada a cada dois meses. Nos animais com anemia ou policitemia a dosagem da hemoglobina glicada não é indicada, porque está diretamente relacionada à quantidade de hemácias (MARCA et al., 2000; KANEKO, 2008).

Os valores para a frutosamina foram obtidos por método cinético colorimétrico, sendo em média de 285,40-399,80 $\mu_{\mathrm{molL}}^{-1}$ para machos e de 269,65$374,80 \mu \mathrm{molL}^{-1}$ para fêmeas. Jensen e Aaes (1992) e Elliott et. al. (1999), estabeleceram valores de frutosamina em cães de 279,70-322,30 $\mu \mathrm{molL}^{-1} \mathrm{e}$ 225,0-375,0 $\mu \mathrm{molL}^{-1}$, respectivamente, semelhantes ao deste estudo e com metodologia adotada de laboratórios humanos.

A determinação da concentração da frutosamina sérica, a cada três ou seis meses, pode ser útil para avaliar o controle glicêmico, para verificar o efeito 
do estresse, elucidar discrepâncias entre histórico, exame físico e glicemia e para avaliar as alterações na insulinoterapia. A concentração da frutosamina sérica não é alterada pelo aumento agudo da glicemia, como ocorre no estresse (ELLIOTT et al., 1999; MARCA, LOSTE, RAMOS, 2000; SAKO et al., 2009).

As concentrações de frutosamina sérica possuem alta correlação com as concentrações de proteína sérica total, como demonstrado por Loste e Marca (1999), os quais sugerem que pequenas variações proteicas, especialmente da albumina, podem interferir significativamente com as concentrações da frutosamina. Zeuqswetter et al. (2010) confirmaram esta importância, ao observar altos níveis de frutosamina em cães com paraproteinemia. Neste estudo, no entanto, os parâmetros bioquímicos dos cães foram normais e as amostras foram refrigeradas, descartando-se a interferência de artefatos.

\section{Conclusão}

Os valores médios obtidos para hemoglobina glicada de 5,35-7,05\% e para frutosamina de 273,51-382,29 $\mu \mathrm{molL}^{-1}$ podem ser utilizados como valores de referência para cães machos e fêmeas adultos, para monitorar o controle glicêmico em cães diabéticos. Os parâmetros estabelecidos segundo metodologias da Sociedade Brasileira de Diabetes, padronizadas para humanos podem ser extrapoladas para cães e disponibilizadas na rotina para laboratórios de Patologia Clínica Veterinária.

Este trabalho foi submetido e aprovado pela Comissão de Ética no Uso de Animais CEUA/SCA protocolo 048/2010.

\section{Referências}

BRIMHAELL, B.; DUERST, M.; JONES, R. T. The amino acid sequence of dog (canis familiaris) haemoglobin. Journal of Molecular Evolution, Portland, v. 9, n. 3, p. 231-235, 1997.
ELLIOTT, D. A.; NELSON, R. W.; FELDMAN, E. C.; NEAL, L. A. Glycosylated hemoglobin concentrations in the blood of healthy dogs and dogs with naturally developing diabetes mellitus, pancreatic beta-cell neoplasia, hyperadrenocorticism, and anemia. Journal of the American Veterinary Medical Association, Schaumburg, v. 211, n. 6, p. 723-727, 1997.

ELLIOTT, D. A.; NELSON, R. W.; REUCH, C. E.; FELDMAN, E. C.; NEAL, L. A. Comparison of serum fructosamine and blood glycosylated hemoglobin concentrations for assessment of glicemic control in cats and dogs with diabetes mellitus. Javma, Chicago, v. 214, n. 12, p. 1794-1798, 1999.

HINDLE, E. J.; ROSTRON, G. M.; CLARK, S. A.; GATT, J. A. Serum fructosamine and glycated haemoglobin measurements in diabetic control. Archives of Disease in Childhood, Londres, v. 61, n. 2, p. 113-117, 1986.

HOENING, M. Comparative aspects of diabetes mellitus in dog and cats. Molecular and Cellular Endocrinology, Londres, v. 197, n. 1-2 p. 221-229, 2002.

JENSEN, A. L.; AAES, H. Reference interval and critical diference for canine serum fructosamine concentration. Veterinary Research Communications, Midlothian, v. 16, n. 5, p. 317-325, 1992.

KANEKO, J. J. Carbohydrate metabolism and its disease. In: KANEKO, J. J.; HARVEY, J. W.; BRUSS, M. L. Clinical biochemistry of domestic animals. San Diego: Academic Press, 2008. p. 45-81.

KAWAMOTO, M.; KANEKO, J. J.; HEUSNER, A. A.; FELDMANN, E. C.; KOIZUMI, I. Relation of fructosamin to serum protein albumin and glucose concentrations in healthy and diabetic dogs. American Journal of Veterinary Research, Chicago, v. 53, n. 5, p. 851-855, 1992.

LOSTE, A.; MARCA, M. C. Study of the effect of total serum protein and albumin concentrations on canine fructosamine concentration. Canadian Journal of Veterinary Research, Ottawa, v. 63, n. 3, p. 138-141, 1999.

MARCA, M. C.; LOSTE, A.; UNZUETA, A.; PÉREZ, M. Blood glycated hemoglobin evaluation in sick dogs. Canadian Journal of Veterinary Research, Ottawa, v. 64, n. 2, p. 141-144, 2000.

MARCA, M. C.; LOSTE, A.; RAMOS, J. J. Effect of acute hyperglycaemia on the serum fructosamine and blood glycated haemoglobin concentrations in canine samples. Veterinary Research Communication, Midlothian, v. 24, n. 1, p. 11-16, 2000. 
PEACOCK, I. Glycosylated haemoglobin: measurement and clinical use. Journal of Clinical Pathology, London, v. 37, n. 8, p. 841-851, 1984.

PLOTNICK, A. N.; GRECO, D. S. Diagnosis of diabetes mellitus in dogs and cats. Veterinary Clinics of North America, Philadelphia, v. 31, n. 5, p. 563-570, 1995.

RUCINSKY, R.; COOK, A.; HALEY, S.; NELSON, R.; ZORAN, D. L.; POUNDSTONE, M. AAHA diabetes management guidelines. Journal of the American Animal Hospital Association, Lakewwod, v. 46, n. 3, p. 215-224, 2010.

SAKO, T.; MORI, A.; LEE, P.; SATO, T.; MIZUTANI, H.; TAKAHASHI, T.; KIYOSAWA, Y.; TAZAKI, H.; ARAI, T. Serum glycated albumin: potential use as na índex of glycemic control in diabetic dogs. Veterinary Research Communication, Midlothian, v. 33, n. 5, p. 473479, 2009.
WANER, T.; HARRUS, S. Anemia of inflamatory disease. In: FELDMAN, B. F.; ZINKL, J. G.; JAIN, N. C. Schalm's veterinary hematology. Lippincott: WileyBlackwell, 2000. 1232 p.

WOOD, P. A.; SMITH, J. E. Elevation rate of glycosylated hemoglobins in dogs after induction of experimental Diabetes mellitus. Metabolism, Boston, v. 31, n. 9, p. 906-909, 1980.

ZEUQSWETTER, F.; KLEITER, M., WOLFESBERGER, B.; SCHWENDENWEIN, I.; MILLER I. Elevated fructosamine concentrations caused by IgA paraproteinemia in two dogs. Journal of Veterinary Science, Seoul, v. 11, n. 4, p. 359-361, 2010. 
